\title{
DA PARALISAÇÃO DOS RINS AO MOVIMENTO DA VIDA: PERCEPÇÕES DE PESSOAS EM TRATAMENTO DE HEMODIÁLISE ${ }^{1}$
}

\author{
From the Kidney's Paralisation to the Life's Movement: \\ the Perceptions Patients of Hemodialysis \\ El Cierre de los Riñones para el Movimiento de la Vida: \\ la Percepción de las Personas en Tratamiento de Hemodiálises
}

\author{
FABÍOLA GuZzo \\ ELISANGELA BÖING \\ ANNE LUISA NARDI
}

\begin{abstract}
Resumo: A insuficiência renal crônica é considerada um grave problema de saúde pública no mundo. Este artigo tem como objetivo conhecer as percepções de pacientes com Doença Renal Crônica (DRC) a partir do seu processo de adoecimento e tratamento. Tem como base para as reflexões o referencial teórico de Carl Rogers, a Abordagem Centrada na Pessoa. Trata-se de uma pesquisa qualitativa, de cunho exploratório e descritivo. $\mathrm{O}$ instrumento utilizado foi uma entrevista semi-estruturada, com o uso de um roteiro contendo uma parte destinada a caracterização do participante e outra composta por questões norteadoras. A partir da análise de conteúdo foram criadas quatro categorias: 1) Percepções sobre Doença e Tratamento; 2) Transformações no Modo de Viver; 3) Recursos de Enfrentamento; 4) Mudanças nas Relações. De forma geral, o estudo apontou que além das mudanças na condição física, que resultam na limitação de atividades laborais e de lazer, evidenciam-se mudanças relacionadas ao estado de humor e maneira de relacionar-se no mundo. A dificuldade de integração da doença como parte da vida mostra-se relacionada à dificuldade de atualização do self. Em contrapartida, o potencial de superação mostra-se relacionado à aceitação das limitações e à construção de um significado positivo para o tratamento.

Palavras-chave: Nefropatias; Diálise renal; Terapia centrada na pessoa.

Abstract: The chronic renal insufficiency is considered a grave problem of public health in the world. This paper has as goal to know the patient's perceptions with chronic renal insufficiency the process of illness and treatment. It has as base the theoretic referential of Carl Rogers, The Person Centered Approach. It is a qualitative research, of exploratory and descriptive nature. The instrument used was a semi-structured interview, with the use of a roadmap containing a part designed to characterize the participant and another composed of guiding questions. From the content analysis it was created four categories: 1) Perceptions of Disease and Treatment; 2) Changes in the Way of Life; 3) Coping Resources; 4) Changes in Relations. Overall, the study found that in addition to changes in the physical condition, resulting in the limitation of labor and leisure activities show up changes related to mood and way of relating to the world. The difficulty of integration of the disease as part of life appears to be related to self-actualization of difficulty before the new condition. In contrast, overcoming potential appears to be related to the acceptance of the limitation and the construction of a positive meaning for the treatment.

Keywords: Kidney diseases; Renal dialysis; Person-centered therapy.

Resumen: La insuficiencia renal crónica se considera un problema grave de salud pública en todo el mundo. Este artículo tiene como objetivo evaluar las percepciones de los pacientes con enfermedad renal crónica (ERC) desde el proceso de su enfermedad y tratamiento. Su base para la reflexión del marco teórico de Carl Rogers, el Enfoque Centrado en la Persona. Se trata de un carácter cualitativo, exploratorio y descriptivo. El instrumento utilizado fue una entrevista semi-estructurada, con el uso de una hoja de ruta que contiene una parte diseñada para caracterizar el participante y otro compuesto por preguntas de orientación. A partir del análisis de contenido que se ha creado cuatro categorías: 1) La percepción de enfermedad y el tratamiento; 2) Los cambios en la forma de vida; 3) recursos de afrontamiento; 4) Los cambios en las relaciones. En general, el estudio encontró que, además de los cambios en la condición física, lo que resulta en la limitación de las actividades laborales y de ocio, se presentó cambios relacionados con el estado de ánimo y la manera de relacionarse con el mundo. La dificultad de la integración de la enfermedad como parte de la vida parece estar relacionada con la auto-realización de dificultad. En contraste, el potencial superación parece estar relacionada a la aceptación de las limitaciones y la construcción de un sentido positivo para el tratamiento. Palabras clave: Enfermedades renales; Diálisis renal; Terapia centrada en la persona.
\end{abstract}

\footnotetext{
Artigo produzido como requisito para conclusão do curso de Residência Integrada Multiprofissional em Saúde do Hospital Universitário Polydoro Ernani de São Thiago - Universidade Federal de Santa Catarina - HU/UFSC.
} 


\section{Introdução}

As pessoas geralmente esperam que a vida seja plena, longa, satisfatória e, acima de tudo saudável, ficar doente não faz parte dos planos de vida. A descoberta de uma doença gera uma série de movimentos internos e externos, como o de definir passos do tratamento e reconhecer-se na nova condição, adequar as expectativas pessoais e de seus familiares sobre tratamento e recuperação, mudanças nos hábitos e na qualidade de vida, além de outras demandas que exigirão da pessoa grande investimento de energia (Castro \& Barroso, 2012). Quando se fala em doença crônica, essa exigência de investimento de energia parece se tornar ainda maior. A Organização Mundial da Saúde (OMS, 2000) define a doença crônica como uma doença permanente ou de longa duração, geralmente com progressão lenta, que produz incapacidade ou deficiência residual, causada por alterações patológicas não reversíveis, que requeira reabilitação ou longos períodos de observação, controle e cuidados.

Os participantes dessa pesquisa possuem doença renal crônica (DRC). Essa doença significa a presença de uma perda lenta, progressiva e irreversível da função dos rins. Até que o paciente tenha perdido cerca de $50 \%$ do funcionamento dos seus dois rins ele permanece praticamente sem sintomas. A partir desse ponto, vários sintomas podem ocorrer, como inchaço, pressão alta, anemia, entre outros (Sociedade Brasileira de Nefrologia, 2014 2 .

A DRC é considerada um importante problema de saúde pública, que se caracteriza por maus resultados e elevados gastos com saúde. Essa doença representa um grande risco para pacientes com diabetes, hipertensão, doença cardíaca e acidente vascular cerebral, que são as principais causas de morte e incapacidade em pessoas mais idosas. Uma vez que a prevalência da doença renal crônica é maior em pessoas mais velhas, o impacto do envelhecimento da população na saúde dependerá, em parte, de como a comunidade renal responde aos tratamentos (Tonelli \& Riella, 2014).

Entre as diversas doenças dos rins, a doença renal crônica pode ser considerada uma das mais temidas, em grande parte, em função da ciência médica não ter cura para tal doença. Uma em cada dez pessoas sofre de alguma forma de doença renal crônica e os índices vêm aumentando nos últimos tempos. As principais causas desse aumento são diabetes, hipertensão, obesidade, fumo e níveis altos de colesterol (Souza \& Pandya, 2014). $\mathrm{O}$ tratamento da doença renal requer dieta especial e uso de medicamentos (Barros, 2004). Este tratamento, com a evolução da doença, atinge de forma considerável a rotina da pessoa, pois consiste em restrições líquidas e alimentares rígidas, além de uso contínuo de diversos remédios

\footnotetext{
2 Disponível em: <http://www.sbn.org.br/publico/tratamento-conservador $>$.
}

e consequente prejuízo no rendimento físico (Rodrigues, Lima \& Amorim, 2004).

A redução da função renal a menos de 10\% caracteriza o estágio terminal dessa função e são necessários tratamentos dialítico e/ou transplante (Barros, 2004). Os tratamentos dialíticos estão disponíveis em diferentes modalidades: diálise peritoneal ambulatorial contínua (DPAC), diálise peritoneal automatizada (DPA), diálise peritoneal intermitente (DPI) ou hemodiálise (HD) (Martins \& Cesarino, 2005).

A hemodiálise, terreno desta pesquisa, é geralmente realizada por períodos de aproximadamente quatro horas e três vezes por semana, em unidades especializadas onde o paciente é conectado à máquina através de acessos venosos. O sangue é bombeado e encaminhado para a máquina onde acontece o processo de filtragem do sangue artificialmente, retornando, então, para o organismo (Velloso, 2001). As mudanças no estilo de vida ocasionadas pela insuficiência renal crônica e pelo tratamento dialítico ocasionam limitações físicas, sexuais, psicológicas, familiares e sociais, que podem afetar a qualidade de vida. Na vivência cotidiana com estes pacientes, os mesmos expressam sentimentos negativos, como medo do prognóstico, da incapacidade, da dependência econômica e da alteração da autoimagem. Por outro lado, eles também reconhecem que o tratamento possibilita a espera pelo transplante renal e, com isso, há uma expectativa de melhorar sua qualidade de vida. As mudanças advindas do tratamento também atingem seus familiares, pois esses necessitam ajustar sua rotina diária às necessidades de apoio ao familiar (Silva, Silveira, Fernandes, Lunardi \& Backes, 2011).

As pessoas, a partir deste momento, passam a vivenciar esta experiência inicial, de maneiras variadas. Cada ser humano traz consigo sua história, sua bagagem cultural, sua forma própria de reagir às condições crônicas de saúde e a necessidade de realização do tratamento. No vivenciar a hemodiálise, a pessoa carrega consigo sua condição física e psicológica, e diversas vezes, renuncia de atividades de ordem social e econômica em função de sua situação patológica (Campos \& Turato, 2010). A partir de uma aproximação com a temática, foi constatado que muitos estudos científicos se debruçavam sobre aspectos relacionados às perdas que as pessoas têm com o início do tratamento, como a perda do trabalho, do convívio social, da autoestima, entre outras (Valle, Souza \& Ribeiro, 2013; Roso, Beuter, Kruse. Girardon-Perlini, Jacobi \& Cordeiro, 2013; Silveira, Pantoja, Silva, Sá, Turiel \& Nunes, 2010), mas constatou-se, nesta revisão de literatura, que não havia estudos focados no potencial de superação dessas pessoas. Assim, a relevância científica deste estudo reside na sua contribuição para a pesquisa e intervenção que possibilitem enfatizar e mapear o potencial de superação dessas pessoas para adequar-se à nova realidade de vida surgida com a doença renal crônica e tratamento. 


\section{A Abordagem Centrada na Pessoa}

Para adentrar na experiência da pessoa com doença renal crônica, a partir do seu processo de adoecimento e tratamento, optou-se pelo olhar da Abordagem Centrada na Pessoa, fundada por Carl Rogers (Rogers, 1983). A premissa de Carl Rogers refere-se à confiança na pessoa como plena de recursos e capaz de se autodirecionar em seu processo de desenvolvimento através da vida. Neste sentido, a filosofia de Rogers se fundamenta na primazia da autoconfiança. Segundo este autor, em todo o ser humano há uma necessidade que se faz evidente em toda a vida humana e orgânica, rumo ao amadurecimento, ao desenvolvimento e ao tornar-se autônoma. O homem é um ser que, independente de sua patologia, mantém posturas frente à vida (Rogers, 1999).

Partindo do pressuposto denominado de tendência à atualização (ou tendência atualizante), na teoria Rogeriana acredita-se que todo organismo é movido por uma tendência inata para desenvolver todas suas potencialidades e para desenvolvê-las de maneira a beneficiar seu crescimento pessoal. A tendência atualizante é o movimento natural em progredir e tem relação com um conjunto de fatores como a visão de mundo e as perspectivas. Ela é positiva no sentido de que todos os seres humanos buscam o melhor para si (Pinto, 2010).

No momento em que se busca compreender como a tendência atualizante se manifesta no indivíduo, é importante deixar de lado juízo e valores, pois o olhar deve ocorrer a partir do referencial de vida daquela pessoa, caso contrário, ela poderá parecer sem sentido. Rogers e Kinget (1977) afirmam que a tendência atualizante procura atingir aquilo que a pessoa percebe como valorizador e enriquecedor, mas não necessariamente ao que é valorizado ao juízo dos outros. Transversalmente ao conceito de tendência atualizante, Rogers (1979) demarca o conceito de Self, descrevendo-o como a inclusão de todas as percepções que a pessoa possui de seu organismo, da sua experiência de vida, da forma como essas percepções interagem com outras percepções e objetos no seu ambiente, e com todo o mundo exterior. Pontua-se que nos primeiros anos de vida, a realidade para as pessoas se resume a sua experiência que passa por um processo avaliativo do mundo em alguns critérios, são eles: o que se percebe sensorialmente como algo agradável é atribuído um valor positivo e o que não é percebido como agradável é atribuído um valor negativo. Rogers nomeou esse processo de avaliação organísmica, quando o indivíduo guia a sua ação a partir de como experiência o mundo no aqui e agora. Da interação entre indivíduo e o contexto onde vive, uma parcela desta experiência se torna "experiência de si”, fazendo com que este, então, crie uma "noção de eu" a partir da qual, também irá guiar suas ações.

Todas as noções adquiridas fazem parte do seu mundo fenomenológico, de maneira que não se trata somente do eu, como existe em realidade, mas do eu como é percebi- do pela pessoa (Rogers, 1977). Então, o conceito de self, também chamado de autoconceito e de noção de eu, é a percepção de si e da realidade pela própria pessoa (Rogers e Kinget, 1977). Em linhas gerais, a tendência atualizante é o movimento, a energia rumo ao desenvolvimento, crescimento, ou conservação que seguirá a direção dada pela noção de self de cada pessoa. Rogers (1977) apresentou outra questão, tendo como solo o existencialismo, e que complementa sua visão de homem: a liberdade, que juntamente com a escolha e responsabilidade estão intrinsecamente ligadas e são inerentes a qualquer ser humano. Está relacionada à coragem, pois ao praticar a liberdade por meio das escolhas, o homem deveria ser corajoso ao entrar no solo das incertezas. A experiência de ser livre é um processo ou aspecto central na abordagem de Rogers, proporcionando mais autonomia, espontaneidade e segurança.

Todavia, essa liberdade tratada por Rogers e Kinget (1977), relaciona-se essencialmente com a experiência. O indivíduo se sente livre para elaborar suas experiências e sentimentos pessoais como ele os entende. $\mathrm{O}$ indivíduo é psicologicamente livre quando não se sente obrigado a negar ou deformar aquilo que experimenta, a fim de conservar o afeto ou o apreço daqueles que possuem um papel importante na sua vida.

Para Rogers e Kinget (1977), o ser humano tem a capacidade, latente ou manifesta, de compreender-se a si mesmo e de resolver seus problemas de modo suficiente para alcançar a satisfação e eficácia necessárias ao funcionamento adequado. Esta capacidade é entendida como parte de sua bagagem natural, e não é produto de alguma educação ou aprendizagem particular, especializada. No entanto, a atualização eficaz desta potencialidade não é automática. Ela requer certas condições, um certo clima interpessoal. O uso desta capacidade requer condições principalmente ligadas às relações humanas: positivas, favoráveis à conservação e valorização do eu, desprovidas de ameaças ou desafio à concepção que o sujeito faz de si.

Através dessa abordagem psicológica, Rogers construiu seu diferencial de psicoterapia sustentado na existência de uma tendência individual para o crescimento e saúde; na ênfase dos elementos emocionais em detrimento dos intelectuais; na priorização do presente em detrimento do passado; e no reconhecimento do papel da relação terapêutica na experiência de crescimento. Em defesa da ideia de que a personalidade humana tende a saúde e ao bem-estar, Rogers desenvolveu atitudes facilitadoras e recursos interventivos que permitem o resgate do potencial realizador existente em todo ser humano (Bacellar, Xavier \& Flôr, 2012).

Partindo dessas concepções é que se buscou uma aproximação das experiências relatadas pelos participantes deste estudo, a fim de refletir sobre como eles têm integrado a doença e tratamento às suas vidas. 


\section{Método}

A abordagem utilizada foi a qualitativa, de cunho exploratório e descritivo. A pesquisa qualitativa preocupa-se com aspectos da realidade que não podem ser quantificados, centrando-se na explicação da dinâmica das relações sociais. Para Minayo (2001), a pesquisa qualitativa trabalha com o mundo de significados, motivos, aspirações, crenças, valores e atitudes, o que corresponde a um campo mais profundo das relações, dos processos e dos fenômenos que não podem ser reduzidos à operacionalização de variáveis.

As informações coletadas nas entrevistas passaram por uma análise de conteúdo categorial temático. Para Minayo (2007, p. 316), "a análise temática consiste em descobrir os núcleos de sentido que compõem uma comunicação cuja presença ou frequência signifique alguma coisa para o objetivo analítico visado". As entrevistas foram lidas na íntegra diversas vezes, através de leitura flutuante, após foram feitos recortes das entrevistas e em seguida elegidas as categorias temáticas conforme os objetivos do estudo.

$\mathrm{Na}$ análise dos dados são apresentados fragmentos das entrevistas dos sujeitos, que são identificados por códigos: letra P (participante) mais enumeração, seguido das letras $\mathrm{M} \mathrm{e} \mathrm{F}$ (masculino e feminino). O estudo foi desenvolvido em uma unidade de tratamento dialítico de um Hospital Universitário, na região Sul do país. A referida unidade conta com uma média de 30 pacientes, divididos em três períodos do dia para realização do tratamento. Participaram deste estudo sete pessoas, quatro do sexo masculino e três do sexo feminino. Estes foram escolhidos por conveniência e como critério de inclusão foi considerado ter disponibilidade, função cognitiva preservada e condição de saúde estável no momento da entrevista. O tempo que os participantes da pesquisa realizam hemodiálise varia de 2 a 8 anos.

Primeiramente foi realizado contato individual com o paciente e explicado sobre o propósito da pesquisa. Após verificação do interesse e disponibilidade da pessoa em participar, a mesma recebeu os esclarecimentos sobre os objetivos da pesquisa, foi informada sobre segurança do anonimato e foi-lhe apresentado o Termo de Consentimento Livre e Esclarecido. Após o aceite e assinatura do mesmo, foi agendado um horário e local para realização da entrevista, dentro da instituição hospitalar.

Esse estudo proporcionou um momento de acolhimento e escuta, permitindo um espaço propício de reflexão, o qual pode trazer benefícios aos participantes. Quanto aos possíveis riscos de abordar questões tão mobilizadoras para as pessoas, como são as relacionadas à saúde/doença/tratamento, foi esclarecido pelo TCLE que em caso de sofrimento emocional durante e após a entrevista, a entrevistadora estaria disponível para prestar a assistência psicológica necessária, realizando acompanhamento posterior aos participantes que realizam hemodiálise na UTD do HU. Ainda, poderiam ser encaminhados para Serviço de Psicologia em Clínica Social ou Clínica Escola, onde $o$ atendimento é gratuito.

O estudo foi realizado através de uma entrevista semi-estruturada, com o uso de um roteiro, contendo uma parte da caracterização do participante, com informações referentes ao sexo, idade, tempo de tratamento, escolaridade e religião. A outra parte foi composta por questões norteadoras referentes às percepções das pessoas sobre as transformações no modo de viver, os recursos de enfrentamento utilizados e a rede de apoio significativa ao longo do processo de adoecimento e tratamento. Em todo o desenvolvimento da pesquisa foi respeitada a Resolução CNS 466/12.

\section{Resultados e Discussão}

Por meio da análise dos dados foram obtidas quatro categorias que emergiram da análise das entrevistas, elencadas e discutidas a seguir: 1) Percepções sobre Doença e Tratamento; 2) Transformações no Modo de Viver; 3) Recursos de Enfrentamento; 4) Mudanças nas Relações.

\section{Categoria 1: Percepções sobre Doença e Tratamento.}

Pôde-se constatar que os participantes do estudo possuem conhecimento diverso sobre a doença e o referido tratamento. Alguns falam de forma apropriada sobre seu diagnóstico, enquanto outros parecem ter uma noção limitada do mesmo, o que pode contribuir para dificuldade de aderência ao tratamento em alguns casos. Infere-se que essa diversidade de conhecimento está relacionada à maneira como cada pessoa recebeu as informações sobre seu diagnóstico e sua percepção de self naquele momento. Seguem alguns fragmentos das entrevistas sobre o momento da comunicação diagnóstica:

Falaram que era só isso, ou aquele que eu te falei que fazia em casa... mas quando o doutor falou que eu precisava fazer (o tratamento de hemodiálise) comecei a chorar, chorar, chorar... porque eu sempre vinha sozinha né, aí no último dia minha cunhada veio comigo pra saber o que eu tinha, o que não tinha, ela dizia não chora dona P, não chora... (P 4 F).

Minha médica foi bem taxativa, "vai ter que fazer uma fistula e essa fístula tem que ficar bem pra poder fazer a hemodiálise". Eu não conseguia aceitar. É muito difícil pra gente saber que tem o problema renal, eu chorei muito... (P 5 F).

A descoberta da doença e necessidade de realizar o tratamento de hemodiálise suscitaram reações de tristeza e desespero. Aqui nota-se o impacto emocional frente a uma experiência completamente nova e que não constituía o self dessas pessoas, sendo que nesse primeiro momento a comunicação pode ser entendida como uma ameaça ao 
self, gerando dificuldade para incorporar isso a sua organização atual. Sabido que a sociedade ocidental, na qual estamos inseridos, preza pela boa forma e funcionalidade do corpo, e que as pessoas se reconhecem e se sentem valorizadas através da avaliação vinda dos outros, receber um diagnóstico de DRC pode estar associado a uma promessa anunciada de falência do corpo e até mesmo de sua identidade, seu "eu". Para Rogers e Wood (1994) o self é a percepção consciente que o "eu" tem de uma parte do campo da experiência total. Consiste no conjunto de ideias, percepções e valores que caracterizam o "eu".

Os participantes trouxeram na sua compreensão sobre o adoecimento e tratamento de hemodiálise a ideia de disfuncionalidade e paralisação, além de uma necessidade de mudança nos hábitos alimentares e de uma nova relação com o corpo, o que aponta para uma nova realidade a ser vivida.

O tratamento é porque o rim esquerdo não tá funcionando normal, não é porque eu só tenho um, é porque ele tá fraco... se eu não fizer mais, ele para, ele não filtra mais o sangue, se eu não fizer, se eu não tiver a máquina, ele para, eu não vou urinar, ele tem uma função especial, que é a função do rim, que é filtrar o sangue e coisarada, se eu não fizer posso morrer, é isso que tô sabendo" (P $3 \mathrm{M})$.

O problema renal é do rim né, os rins vão parando, e eu tenho que me alimentar, fazer uma dieta especial, tem que tirar o sal, não pode tomar muito líquido, tem que fazer muita dieta... Eu sei que é tipo uma filtração, filtra o sangue, entra na máquina e ela faz aquele processo de tirar as coisas ruins do sangue, resíduos, a água que a gente toma tem que diminuir o líquido, tem que perder peso, é filtrar o sangue (P $5 \mathrm{~F}$ ).

Paradoxalmente à ideia de disfuncionalidade e paralisação, os pacientes também veem na hemodiálise a chance de continuarem vivos. É quase unânime a percepção de que a hemodiálise - a máquina - é a tecnologia da qual dependem para viver, o que traz, muitas vezes, a ideia de obrigatoriedade e de aprisionamento ao tratamento.

Segundo Silva et al. (2011) a hemodiálise pode acarretar sentimentos ambíguos de aceitação e revolta nas pessoas que precisam deste tratamento para sobreviver, pois ao mesmo tempo em que ele garante a vida, torna a pessoa dependente da tecnologia. Existe um simbolismo atribuído à hemodiálise, tratando a mesma como uma relação de "vida e morte", ponderando que a sobrevivência é possível pelo procedimento.

É um negócio que você está preso pelo resto da vida até a hora de partir de vez... Eu gosto do ambiente aqui, me acostumei, está tudo bem, venho aqui dia sim dia não (P $2 \mathrm{M}$ ).
O que eu sei é que tem que se cuidar né, que não é uma doença muito boa né. Diz que se não se cuidar prejudica muita coisa no corpo da pessoa... É um tratamento bom, a gente sabe que se quiser viver tem que enfrentar, que é obrigada (P 4 F).

É uma sobrevida, sem isso a gente não consegue viver, eu posso optar por não fazer, mas aí a opção vai me levar à morte... Eu não tenho nada contra a hemodiálise, mas é uma coisa chata, te acarreta outras coisas, é uma obrigação... Eu vejo como um mal necessário, não é uma coisa boa, no começo inclusive eu passei muito mal tive vários problemas, esse ano tive pressão alta, pressão baixa, tive convulsão. É mais ou menos que nem médico e advogado: é melhor que não tivesse, mas infelizmente a gente precisa (P 7 M).

A maioria dos pacientes visualiza a hemodiálise como uma obrigação, pois possuem a compreensão de que não há outra alternativa para continuarem vivos. No entanto há uma escolha a ser feita pela pessoa que está semanalmente dentro do hospital, ligada à máquina de hemodiálise por aproximadamente 4 horas do seu dia, de 2 a 3 vezes na semana. $O$ paciente precisa fazer um movimento em direção ao que considera o melhor para si naquele momento. Mesmo sofrendo as reações adversas do tratamento (mal-estar, náuseas, tonturas) decide realizar a hemodiálise, prevalecendo assim o movimento em direção à sobrevivência e desenvolvimento.

Sob a ótica da Abordagem Centrada na Pessoa, podemos pensar aqui a questão da liberdade, que inclui escolha e responsabilidade, sendo estas disponíveis a todos os seres humanos. Ficou claro que, para essas pessoas, junto à sensação de aprisionamento existe um impulso rumo à vida, há busca por uma melhor condição de saúde e bem-estar. Segundo Rogers (1999), há uma necessidade que se manifesta em toda a vida, humana e orgânica, rumo ao amadurecimento, ao desenvolvimento e ao tornar-se autônoma. O homem é um ser que, independente de sua patologia, mantém posturas frente à vida, pautadas na sua noção de self e no seu nível de percepção da liberdade e responsabilidade pelas escolhas.

Uma alternativa que surge ao paciente em tratamento de hemodiálise é o transplante renal. Para chegar até ele existe um caminho a ser percorrido e nesse caminho está a questão do tempo, a necessidade de entrar em uma lista de espera, de buscar um doador compatível. Uma soma de fatores precisa ser levada em conta, incluindo a condição física do paciente, como num jogo de montar, onde as peças precisam se encaixar com perfeição.

Eu quero fazer o transplante, tô na fila há 2 anos, eu quero me livrar disso... só que eu tenho um problema que eu sou $A B$ positivo, que é raro, só posso receber do mesmo tipo de sangue que o meu (P M 7). 
Eu tenho esperança de botar o pé, fazer o transplante renal... Sim, eu sempre fui uma pessoa positiva, minha irmã também é muito inteligente, me dá muita força... já to na fila do transplante do rim, vou consultar, dia primeiro, na médica do transplante (P F 5).

A possibilidade de realizar o transplante parece servir como recurso para enfrentar a realidade no momento, sendo esta realidade ligada à condição de doença e hemodiálise. Porém, se a pessoa permanece unicamente focada nessa possibilidade futura, corre-se o risco de não se permitir viver o agora de forma plena, dificultando a eficácia da tendência de atualização. A imagem de si arraigada no passado ou a imagem de si projetada para o que deseja no futuro, dificulta a atualização do "eu" de modo realístico, a possibilidade de viver o aqui e agora, com tudo que ele tem para oferecer, coisas boas e ruins.

\section{Categoria 2: Transformando o Modo de Viver}

Os participantes identificaram mudanças significativas no seu modo de viver. Os relatos revelam, a princípio, perdas relacionadas às limitações físicas, que acabam impedindo a realização de atividades laborais e também de lazer, levando as pessoas para o afastamento do convívio social devido à incompatibilidade entre aquilo que gostariam de ser e fazer, e aquilo que são e que conseguem fazer. Os excertos a seguir parecem confirmar estas reflexões:

Causou um monte de problema, agora não posso trabaIhar, não posso mais fazer esforço físico, trabalhar com picareta, com pedra, como eu fazia, não posso mais, só com coisa leve... meu filho mais novo e meu sobrinho querem aprender a trabalhar de pedreiro agora, e eu só oriento, e eles vão lá e fazem. Mas eu preferia tá fazendo toda vida (risos) (P M 3).

Mudou bastante né... eu era uma pessoa trabalhadeira, que levantava de manhã, deixava todo mundo dormir e ia limpar o banheiro, já ia lavar uma louça, levar um lixo lá fora, hoje não posso pegar saco pesado. Ah Deus como mudou (P F 4).

Mudou bastante. Eu acordava quatro horas da manhã e saia às sete pra casa... trabalhava em Biguaçu, trabalhava o dia todo, carregava peso, alumínio... Era puxado, mas eu adorava né (P M 6).

Essas falam corroboram com Mattos e Maruayma (2009) quando referem o trabalho como uma das instâncias da vida na qual as pessoas mais investem suas energias, físicas e emocionais, sobretudo na sociedade atual, onde o consumo é fortemente valorizado. As pessoas, muitas vezes, são reconhecidas apenas através do desempenho pelo seu trabalho. Aliado a isso, apesar das configurações familiares estarem mudando, ainda há um ideal de constituição de família nuclear, ou seja, aquela em que a mulher desempenha o papel de dona de casa e mãe, e o homem de pai, marido e provedor do lar, sendo reconhecido perante a comunidade por conseguir realizar satisfatoriamente esses papéis.

A percepção do eu (self) aparece nos discursos bastante atrelada à funcionalidade do corpo e a disponibilidade para o trabalho e, em decorrência disso, após o aparecimento das limitações físicas parece emergir uma incongruência entre a experiência organísmica (o corpo num ritmo diferenciado, sentindo dores, necessitando de adaptação) e sua noção de eu (fundamentada em um corpo silencioso e a serviço do trabalho, útil, belo), evidenciando a dificuldade de integração da doença como parte da vida.

Quando o self não está em consonância com a experiência vivida, há um desequilíbrio entre a experiência do sujeito e a percebida pelo organismo. Esse desequilíbrio ocorre, para Rogers (1977), a partir de uma introjeção de valores que não são propriamente da experiência vivida, mas de uma série de exigências feitas pela sociedade. Exigências essas, que na fala dos entrevistados, estão relacionadas ao ser homem, chefe e provedor do lar, a ser mulher, dona de casa e responsável pelo cuidado dos filhos, a ter um corpo útil para o trabalho e desprovido de deficiências.

Além das mudanças na condição física, que resultam na limitação de atividades laborais e de lazer, ficaram evidentes mudanças relacionadas ao estado de humor e maneira de relacionar-se no mundo.

Eu te diria que sim, eu acho que mudei... eu acho que eu tô mais fechado, mais quieto, não seria depressivo, mas parecido com isso, não tão expansivo... não sei se é a idade também, pode ser isso (P M 7).

Tenho vontade de ficar calado, sem barulho, sem nada. Fico nervoso quando o negócio não dá certo, quando imagino uma coisa e não dá certo (P M 6).

Os indivíduos cujo self não 'combinam' com seus sentimentos e experiências precisam se defender contra a verdade, porque a verdade lhes traz ansiedade. Devido à necessidade de se proteger dos seus temores mais íntimos, o indivíduo pode se comportar de maneira destrutiva, regressiva, imatura e prejudicial (Rogers, 1977).

Nesse sentido, Laplantine (2010) discute como a doença pode ser vista a partir de um modelo maléfico ou benéfico. No primeiro, a doença é vista como um mal absoluto, é nociva, perigosa, indesejável, privadora, da ordem do anormal e deve ser combatida, seja por remédios, seja por outros tipos de terapias, como as psicológicas. Além disso, a doença configura-se como um desvio, tanto biológico quanto social. Já o modelo benéfico, traz a ideia de que o sintoma é uma mensagem a ser escutada e desvendada. A doença, por isso, tem um sentido e serve como uma tentativa de restauração do equilíbrio alterado. Outra característica atribuída dentro desta visão benéfica 
é de que esse momento possibilita a vivência de outras experiências, as quais os sujeitos não conseguiriam devido à rotina intensa e agitada de trabalho.

Há males que vem pra bem, enquanto não causou essa da cirurgia, esse negócio... Antes eu queria fazer as coisas, arrumar a casa, comprar as coisas pra família e não conseguia, e agora não... depois disso aí deu uma reviravolta pro bem, eu consegui minha casa nova, consegui os móveis novos, tá tudo bem mais organizado (P M 3).

Além disso, algumas pessoas enfatizaram a diminuição dos sintomas anteriores à realização da hemodiálise, sendo que o tratamento proporcionou alívio e maior bem-estar. As pessoas que aceitam as limitações do corpo demonstram vivenciar o adoecimento com maior tranquilidade e conforto.

Estou me sentindo bem, venho aqui e faço a hemodiálise e naquela noite eu durmo bem (P F 1).

Antes de fazer esse procedimento eu sentia muita câimbra, dores na perna, tinha muito inchaço, depois eu melhorei, depois disso até a câimbra melhorou... Eu tinha até medo de dormir, tinha caimbra no dedo, na panturrilha, passava até quase sem dormir por medo de uma reação diferente e não acordar mais normal. Tinha medo, agora me sinto tranquilo... (P M 3).

Para aqueles que encontram um significado positivo para o tratamento, a doença se torna mais uma parte de suas vidas que se une a tantas outras, trazendo à tona 0 potencial existente dentro de cada ser. Nesse sentido, Rogers (1977) ressalta que quanto menor for a rigidez da percepção de si e da realidade, maior a capacidade de atualização do self, e maior será o uso da potência em direção ao funcionamento saudável. A construção do self é movimento, processo e, esse movimento de transformação centrado no contato consigo, na necessidade de rever-se e rever a vida de modo intenso e contínuo, gerado pela doença e pela hemodiálise, pode impulsionar a atualização do self.

\section{Categoria 3: Encontrando Recursos de Enfrentamento}

Foi possível identificar nas falas dos participantes que as crenças religiosas são importantes recursos no enfrentamento das situações difíceis suscitadas pela DRC. A maioria dos pacientes relatou fazer parte de alguma religião e enfatizou o quanto as crenças religiosas servem de suporte e conforto para tolerar as angústias advindas do adoecimento e tratamento. É sabido que, partindo das construções culturais mais distintas, as religiões buscam, em seu âmago, explicações para questões essenciais à experiência humana. No presente estudo, a religião surgiu como principal recurso no enfrentamento da doença e tratamento, sendo que alguns participantes relataram que antes do adoecimento já possuíam alguma crença religiosa, e outros descobriram sua fé diante do sofrimento emocional causado pela doença.

Mudou, depois que aconteceu isso, uns 3 ou 4 anos aí que eu entrei pro Evangelho... Devido a religião eu acho que me ajuda muito, Deus me dá tranquilidade nos momentos difíceis, eu oro muito pedindo as coisas, eu sou um pedilão danado... (P M 2).

Primeiramente eu acredito muito em Deus, eu confio em Deus, e segundo depois eles aqui que são os anjos na terra, isso aí é Deus que dá, essa atividade pra eles, esse dom da enfermagem pra poder curar o ser humano... eu considero 100, se não é eles aqui a gente não sobrevive não (P M 3).

Eu sou muito esperançosa, eu tenho muita fé, eu rezo muito, Deus é muito bom comigo... eu perdi o pé, perdi pelo problema renal, mas o importante pra mim é que eu tenho a vida, tenho minha visão, posso olhar, ver minha neta, curtir minha família... e minha família é maravilhosa, é linda, todo mundo querendo me ajudar (P F 5).

Vários pesquisadores têm investigado a associação entre fatores relativos à religiosidade, como práticas, afiliações e crenças, e suas implicações na saúde, tanto em sua dimensão física quanto mental (Faria \& Seidl, 2005). Essa associação tem raízes histórico-culturais muito antigas, presentes em mitos gregos, em rituais indígenas e nas inscrições bíblicas, que seguem influenciando a cultura ocidental nos tempos modernos. Para Boff (2006) as religiões têm como base a experiência com uma realidade mística e fascinante que se apodera do ser humano, manifestando a presença de algo transcendente que é sentido no cotidiano da existência humana e possui capacidade para transformar a vida. A espiritualidade refere-se a essa experiência de contato com algo que transcende as realidades da vida terrena. Ficou evidente que para os participantes deste estudo existe uma implicação positiva da religião e espiritualidade na vivência do adoecimento.

Nas falas a seguir aparece certa flexibilidade da percepção em relação às limitações físicas e mudanças no cotidiano, como a aceitação de que atividades que antes eram realizadas sozinho, já não são mais possíveis. Apesar do aparecimento dessa parcela de flexibilidade, parece haver um importante esforço em distanciar-se da dor e sofrimento, um "não querer pensar" nos acontecimentos considerados difíceis e indesejáveis, que pode impedir que a experiência seja vivida totalmente. A utilização integral da potência depende da aproximação ao self real, e isso só pode ocorrer quando a pessoa permite-se ser quem é, e não quem se quer ser. 
Eu tenho esperança de botar o pé, de fazer o transplante... negativo é que eu perdi o pé, eu não vou me abalar por causa disso, não posso ficar pensando negativo. Se eu posso pensar positivo, vou deixar as coisas ruins pra lá... Foi uma coisa boa pra mim não perder a vida, se eu fui obrigada a tirar o pé. Que eu vou conseguir o transplante e a prótese, porque se eu for me abalar, ficar chorando num canto, eu não vou conseguir (P F 5)

O que eu não posso é me encolher num canto e ficar chorando, porque muita gente entra em depressão... tem um monte de coisa que pode fazer. Fazer uma comi$d a$, varrer um quintal... isso desde moleque eu aprendi ajudando a mãe em casa. Minha esposa trabalha, mas ninguém passa fome, cada um se vira, porque desde pequenino eu ensinei meus filhos: tua mãe não tá em casa vai lá e frita um ovo... porque se eu sou uma pessoa que não ensina meus filhos, hoje com minha situação, eu ia ter dificuldades... (P M 3).

A crença religiosa e a expressão da fé parecem proporcionar algum significado aos momentos difíceis pelos quais as pessoas passam, sendo que buscam colocar as decisões pelos acontecimentos na "terra" a cargo de Deus, bem como o poder para solucionar os problemas. A religião pode servir como importante recurso de enfrentamento diante das adversidades e falta de "explicação" para aquilo que nós, seres humanos, não somos capazes de compreender. Por outro lado, ela pode afastar o indivíduo de uma percepção mais realística de sua experiência organísmica, colocando a potência em algo externo, e que precisa ser encontrada fora de si.

\section{Categoria 4: Mudanças nas Relações}

Ao longo desse estudo pôde-se perceber que as relações sociais e de amizade representam certa ameaça à imagem que os indivíduos têm de si, sendo bastante difícil para estes aceitar e buscar novas formas de relacionar-se frente às limitações resultantes do adoecimento. Quando cessa o movimento ao encontro dos amigos, o que resta são as relações íntimas no meio familiar. Presente nos relatos está a marca da impotência e a necessidade de receber ajuda, a expectativa de ser cuidado, direcionado, conduzido, um entregar-se ao outro. Nessa posição, o indivíduo vai deixando-se levar, sem troca, sem se doar, pois parece já não reconhecer algo em si que seja interessante para o outro. Dessa forma, mais uma vez sua potência parece ser colocada no outro, já que não reconhece outra forma de se relacionar senão aquela que carrega do passado.

Aí tem muitas coisas que mudaram. Minha esposa vem sempre me acompanhar, mudou tudo lá em casa. Hoje é uma filha que trabalha, ela levanta mais cedo para preparar o almoço pra nós (P M 2).
A família ajuda né, dá uma força, se eu preciso comprar um remédio vão lá e compram (P F 4).

Com certeza. Antigamente, como eu tinha meu pé, era normal, hoje elas me visitam mais, elas me cuidam bem, tem aquela preocupação de fazer uma dieta sem sal... Quando vou na casa das minhas irmãs elas já tiram o sal da comida, elas dizem: "cada um coloca o sal na sua comida”, elas são preocupadíssimas comigo, me ajudam bastante nessa parte (P F 5).

Devido a maior dependência física, as pessoas adoecidas, por vezes, deixam de frequentar locais que antes lhe ofereciam lazer e bem-estar, e com o tempo afastam-se dos amigos, restringindo o convívio social e deixando, aos poucos, de existir nas relações. Aproximar-se dos amigos requer um movimento que exige contato com aquilo que não se é mais e que talvez seja difícil de aceitar. Como existir não podendo compartilhar mais da mesma comida, da mesma bebida, da mesma festa ou programa na praia?

No fragmento a seguir o participante parece ter mantido seu foco nas atividades e forma de relacionar-se anteriores ao adoecimento, tendo certa dificuldade em incluir novas perspectivas de interação social na sua vida. Quando a pessoa não consegue atualizar a imagem que tem de si, fica apegado a uma visão de si anterior ao adoecimento, tornando sua forma de relacionar-se condicional a visão de si do passado (expressão de um selfideal).

Não tenho... nosso relacionamento social hoje seria a igreja e a família, pessoas de fora não... A gente não sai, eu sempre gostei de ficar em casa, mas nem sempre foi tanto assim. É difícil vir alguém visitar, a minha mãe vem de 2 a 3 meses porque ela mora em Porto Alegre, a mãe dela é muito difícil vir... A gente acabou se fechando, tu te restringe pra comer, ta com menos dinheiro porque não ta trabalhando, ela parou também pra cuidar de mim... quer queira quer não, menos dinheiro, menos atividade social... não pode comer, não pode beber (P M 7).

Neste excerto evidencia-se uma dificuldade em se deparar com as limitações físicas, ou melhor, com aquilo que deixou de ser. Manter o contato social, visitar amigos, expor a fragilidade do corpo parece representar a confirmação de que algo mudou, gerando sofrimento, culminando em um movimento de manter-se afastado, numa tentativa de se proteger e manter sua percepção de si mais intacta e estável possível. Os resultados desse estudo, de forma geral, apontam para uma dificuldade das pessoas em integrar a DRC às suas vidas, principalmente quando a doença implica perda ou limitação da capacidade física. Nossa sociedade parece não conseguir associar a ideia de um corpo "doente" à de uma vida de novas possibilidades, que possa ser vivida satisfatoriamente, mesmo com sofrimento. Apesar de alguns participantes relatarem certa 
aceitação diante da doença e tratamento, essa aceitação vem sempre acompanhada de uma condição, uma expectativa de alcançar outra condição de saúde no futuro. Essa expectativa aparece associada à religiosidade, que muitas vezes pode servir como um importante recurso no enfrentamento da DRC. No entanto, pode contribuir para que a pessoa se distancie de uma percepção de self real e perca de vista seu próprio potencial de superação frente às adversidades da vida.

\section{Considerações finais}

A doença renal crônica é uma doença progressiva e seu tratamento exige grandes e intensas mudanças na vida das pessoas. A maioria delas deixa de realizar atividades de lazer e trabalho devido à fragilidade física, fato que gera grande impacto emocional, já que a maioria das pessoas tem a imagem de si associada à capacidade laboral. Quando essa capacidade não é mais a mesma, surge no indivíduo a necessidade de movimentar-se (tendência atualizante) de maneira diferente pela vida.

Ao longo desse estudo, foi possível conhecer um pouco do modo como os participantes vêm se movimentando na vida após o surgimento da DRC e tratamento de hemodiálise. As pessoas relataram dificuldade para lidar com o adoecimento, principalmente quando esse gera limitações para o corpo. O corpo, aqui, aparece como uma ferramenta que garante a possibilidade de alcançar todo sucesso, bem-estar e satisfação que a pessoa possa ter na vida. É o corpo, através de seu desempenho, que permite a valorização e o reconhecimento pelos outros.

Por vezes, as pessoas acabam se afastando do convívio social devido as limitações e não aceitação da nova condição de saúde, e parece não perceber algo em si que possa ser interessante para o outro e, aos poucos, vão se anulando na relação. Foi possível constatar que as crenças religiosas são importantes recursos no enfrentamento das situações difíceis suscitadas pela DRC. Por outro lado, ela pode afastar o indivíduo de uma percepção mais realística de sua experiência organísmica, quando as pessoas colocam a potência em algo externo e que precisa ser encontrada fora de si.

A DRC e o tratamento de hemodiálise colocam o indivíduo de uma forma bastante intensa em contato com seu “eu”, fazendo com que se depare, semanalmente, com sensações que na maioria das vezes não pertencem à imagem de si. Enquanto a pessoa não estiver aberta para essas experiências e não flexibilizar suas percepções, estará se afastando do seu self real e dificultando a eficácia plena de sua potência rumo ao desenvolvimento, amadurecimento e funcionamento saudável.

O processo de atualização acontece através de condições facilitadoras nas relações interpessoais. Um clima facilitador pressupõe o não julgamento e a permissão para que a pessoa expresse livremente seu "eu", sem ameaças. Essa relação pode acontecer entre todos os envolvidos no processo de adoecimento e tratamento: paciente, família, profissionais de saúde, amigos. O psicólogo nesse ínterim aparece como a pessoa que pode contribuir com a identificação e fortalecimento dessas condições facilitadoras, propiciando um espaço de escuta acolhedor, livre de ameaças e julgamentos, onde o sujeito possa se deparar com a realidade do adoecimento e tratamento, e refletir sobre suas escolhas e responsabilidades nesse processo.

Importante salientar algumas dificuldades encontradas durante o estudo, estas principalmente relacionadas ao campo da pesquisa. As entrevistas foram realizadas nos dias em que os participantes iam ao hospital fazer o tratamento de hemodiálise, sendo que a maioria depende de transporte municipal para chegar até o local e não poderiam comparecer em outro dia. Foram identificados sinais de ansiedade nos participantes, relativa ao tempo de duração da entrevista, sabido que necessitavam realizar a hemodiálise durante 3 ou 4 horas e tinham horário marcado para apanhar o transporte para voltar para casa. Em alguns momentos, notou-se certa rapidez para responder a algumas perguntas e também certo receio em prolongar os temas, o que pode ter interferido no aprofundamento e qualidade das respostas dadas pelos participantes. Além disso, as salas utilizadas para realização das entrevistas são compartilhadas por vários profissionais, sendo que em vários momentos houve a necessidade desses entrarem para pegar algum material, fato que acabava interrompendo o fluxo da entrevista.

Apesar das dificuldades encontradas, o estudo permitiu uma aproximação das vivências e percepções das pessoas com doença renal crônica em tratamento hemodialítico. Há necessidade de novas pesquisas que ampliem o foco das perdas e qualidade de vida, para conhecer e compreender o potencial existente em cada ser rumo ao seu crescimento e funcionamento saudável, mesmo diante do sofrimento. Quanto mais, os profissionais da saúde, conhecerem as dificuldades e capacidades dos pacientes, mais conseguirão atuar de maneira acolhedora e eficiente, identificando e auxiliando as pessoas a desenvolverem condições para que possam encontrar sua potência na vivência do adoecimento e tratamento de hemodiálise, apoderando-se de suas próprias vidas.

\section{Referências}

Bacellar, A, R., Joana S. X. \& Flôr, M. S. (2012). Abordagem centrada na pessoa e políticas públicas de saúde brasileiras do século XXI: uma aproximação possível. Revista do NUFEN, $4(1), 127-140$.

Barros, T. M. (2004). Doença Renal Crônica: do doente e da dimensão familiar. In Mello, Júlio Filho. \& Burd, Miriam. (Orgs.) Doença e família (357-364). São Paulo: Casa do Psicólogo. 
Boff, L (2006). Espiritualidade: um caminho de transformação. Rio de Janeiro: Sextante.

Campos, C. J. G., \& Turato, E. R. (2010). Tratamento hemodialítico sob a ótica do doente renal: estudo clínico qualitativo. Revista Brasileira de Enfermagem, 63(5), 799-805.

Castro, M. M. Cavalcante \& Barroso, C. L. (2012). Contribuições da terapia cognitivo-comportamental nos cuidados paliativos. Revista Psicologia, Diversidade e Saúde (Salvador), dez, vol. 1(1): 101-108.

Faria, J. B. \& Seidl, E. M. F. (2005). Religiosidade e enfrentamento em contextos de saúde e doença: revisão da literatura. Psicologia Reflexão e Crítica, 18(3), 381-389.

Laplantine, F. (2010). Antropologia da doença. São Paulo: Martins Fontes.

Martins, M. R. I. \& Cesarino, C. B. (2005). Qualidade de Vida de Pessoas com Doença Renal Crônica em Tratamento Hemodialítico. Revista Latino Americana de Enfermagem. 13(5), 670-676.

Mattos, M. \& Maruyama, S.A.T (2009). A experiência em família de uma pessoa com diabetes mellitus e em tratamento de hemodiálise. Rev. Eletronica Enfermagem, 11(4), 971-8.

Minayo, M. C. S. (2001). Pesquisa Social: Teoria, método e criatividade. Petrópolis: Vozes.

Minayo, M. C. S. (2007). O desafio do conhecimento. São Paulo: Hucitec.

Pinto, M. A. S. (2010). A abordagem centrada na pessoa e seus princípios. In Carrenho Esther; Tassinari, Márcia; Pinto, Marcos, Alberto. Praticando a abordagem centrada na pessoa: Dúvidas e perguntas mais frequentes (57-83). São Paulo: Carrenho Editorial.

Rodrigues, R. T. S., Lima, M. G. S. \& Amorim, S. F. (2004). A prática da psicologia hospitalar na Santa Casa de São Paulo: novas páginas de uma antiga história. São Paulo: Casa do Psicólogo.

Rogers, C. R (1951). A terapia centrada no cliente. São Paulo: Martins Fontes.

Rogers, C. R (1961). Tornar-se pessoa. São Paulo: Martins Fontes.

Rogers, C. R (1977). De pessoa para pessoa: o problema de ser humano, uma nova tendência na psicologia. São Paulo: Pioneira, $2^{\text {a }}$ edição.

Rogers, C. R \& Kinget, M. G. (1977). Psicoterapia e Relações Humanas. Belo Horizonte: Interlivros.

Rogers, C. R (1979). O tratamento clínico da criança problema. São Paulo: Martins Fontes.

Rogers, C. R. (1983). Um Jeito de Ser. São Paulo: EPU.

Rogers, C. (1994). As condições necessárias e suficientes para a mudança terapêutica da personalidade. In: Wood John. K, Abordagem centrada na pessoa (p. 155-177). Vitória: Editora Fundação Ceciliano Abel de Almeida.
Roso, C. C., Beuter, M., Kruse., M. H. L, Girardon-Perlini, N. M. O., Jacobi, C. S., \& Cordeiro, F. R. (2013). O cuidado de si de pessoas em tratamento conservador da insuficiência renal crônica. Texto \& Contexto-Enfermagem, 22(3), 739-745.

Silva, A. S., Silveira, R. S., Fernandes, G. F. M., Lunardi, V. L., \& Backes, V. M. S. (2011). Percepções e mudanças na qualidade de vida de pacientes submetidos à hemodiálise. Revista Brasileira de Enfermagem, 64(5), 839-844.

Silveira, C. B, Pantoja, I. K. O. R, Silva, A. R. M, Azevedo, R. N, Sá, N. B, Turiel, M. G. P. \& Nunes, M. B. G. (2010). Qualidade de vida de pacientes em hemodiálise em um hospital público de Belém - Pará. Jornal Brasileiro de Nefrologia, 32(1), 39-44.

Souza, E. \& Pandya, S. (2014). Previna-se: Salve seus rins. Guia completo para pacientes renais ( $1^{\circ} \mathrm{ed}$.). Editor Rajkot Índia.

Tonelli, M. \& Riella, M. (2014). Doença renal crônica e o envelhecimento da população. Jornal Brasileiro de Nefrologia, $36(1), 1-5$.

Valle, L. S., Souza, V. F. \& Ribeiro, A., M. (2013). Estresse e ansiedade em pacientes renais crônicos submetidos à hemodiálise. Estudos de Psicologia (Campinas), 30(1), 131-138.

Velloso, R. L. M. (2001). Efeitos da hemodiálise no campo subjetivo dos pacientes renais crônicos. Cógito, 3, 73-81.

Fabíola Guzzo - Graduada em Psicologia pela Universidade Regional Integrada do Alto Uruguai e das Missões (Erechim/RS), com Residência em Saúde (Alta Complexidade), pela Universidade Federal de Santa Catarina. Endereço Institucional: Universidade Federal de Santa Catarina. Rua Tico Tico, Bairro Ingleses do Rio Vermelho, Florianópolis SC. CEP 88058-720. Email: fabiolaguzzo.psi@gmail.com

Elisangela Böing - Graduada em Psicologia pela Universidade Federal de Santa Catarina, com Especialização em Saúde da Família/Modalidade Residência pela Universidade Federal de Santa Catarina; Mestrado e Doutorado em Psicologia pela Universidade Federal de Santa Catarina. Docente do Departamento de Psicologia/ UFSC, integrante do Laboratório de Psicologia da Saúde, Família e Comunidade (LABSFAC/UFSC).

Anne Luisa Nardi - Possui Graduação em Psicologia pela Universidade Comunitária Regional de Chapecó, Mestranda do Programa de Pós-Graduação em Psicologia da Universidade Federal de Santa Catarina, com Especialização em Psicologia Clínica na Abordagem Centrada na Pessoa (2014). Servidora da Universidade Federal de Santa Catarina, atuando como psicóloga do Serviço de Psicologia do Hospital Universitário Professor Polydoro Ernani de São Tiago - HU/UFSC. Preceptora do Programa de Residência Integrada Multiprofissional em Saúde HU/ UFSC. Membro do Grupo de Trabalho Humanização HU/UFSC.

Recebido em 16.03.2016 Primeira Decisão Editorial em 24.08.2016 Aceito em 24.10.2016 